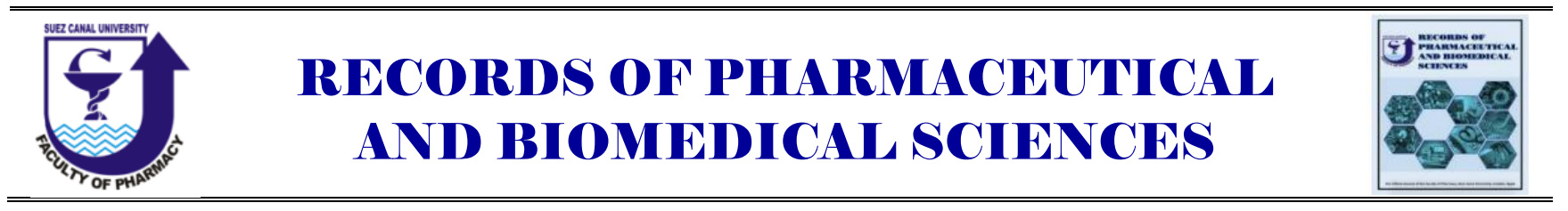

\title{
Obesity and Type 3 Diabetes: Nutritional Approaches and Therapeutic Implication
}

\author{
Hoda E.Mohamed ${ }^{a}$, Dina M. Abo-ELmatty ${ }^{b}$, Noha M. Mesbah ${ }^{b}$, Samy M. Saleh $^{b}$ and Amr T. Sakr ${ }^{c}$ \\ ${ }^{a}$ Department of Biochemistry, Faculty of Pharmacy, Zagazig University, ${ }^{b}$ Department of Biochemistry, \\ Faculty of Pharmacy, Suez Canal University, ${ }^{c}$ Ministry of Health, Zagazig, Sharkia, Egypt
}

Received on: 21.03. 2019

Revised on: 17. 05. 2019

Accepted on: 21. 05. 2019

Correspondence Author:

Tel:+ 20552361866

E-mail address:

amrotawfik242@gmail.com

\begin{abstract}
Obesity is a proven risk factor for neurodegenerative disease like Alzheimer's disease (AD). Accumulating evidences suggested that nutritional interventions provide potential for prevention and treatment of $\mathrm{AD}$. The present study aimed to investigate the effect of dietary treatment of obese rats with natural Raspberry ketone (RK) and their relationship with neurodegeneration. Obesity was first induced in 40 male Wistar rats $(140-160 \mathrm{~g})$ by feeding high fat diet (HFD) for 16 weeks. Obese rats were then assigned into 4 groups ( $\mathrm{n}=10$ each). $(\mathrm{O}-\mathrm{AD})$ is obese induced AD group maintained on HFD for another 6 weeks. OCR is obese group received calorie restricted diet for 6 weeks. OCRRK is obese group received calorie restricted diet and RK ( $44 \mathrm{mg} / \mathrm{kg}$ body weight, daily, orally) for 6 weeks and OCRD is obese group received calorie restricted diet and orlistate $(10 \mathrm{mg} / \mathrm{kg}$ body weight, daily orally) for 6 weeks. Another 10 normal rats received normal diet were used as normal control group (NC). Body weight, visceral white adipose tissue weight (WAT), lipid profile, oxidative stress markers, adiponectin, cholinergic activity and amyloid extracellular plaques were examined. In addition to histological changes in brain tissues were evaluated. Raspberry ketone (RK) via its antioxidant properties attenuated oxidative damage and dyslipidemia in O-AD group. It inhibited acetylcholinesterase enzyme (AchE) and hence increased acetylcholine level (Ach) in brain tissues of O-AD rats. It is also impeded the upregulation of beta-secretase-1 (BACE-1) and the accumulation of amyloid beta $(\mathrm{A} \beta)$ plaques which crucially involved in $\mathrm{AD}$. The combination of $\mathrm{CR}$ diet with RK was more effective than CR diet with orlistate (antiobese drug) in abrogating the neurodegenerative changes induced by obesity. Results from this study suggested that concomitant supplementation of RK with calorie restricted regimen effectively modulate the neurodegenerative changes induced by obesity and delay the progression of AD.
\end{abstract}

Keywords: Alzheimer's disease, Raspberry ketone, Cholinergic activity, Amyloid plaques, Orlistate.

\section{Introduction:}

The prevalence of obesity has significantly increased during the last decades reaching epidemic proportions in many countries (Valdecantos et al.,
2009). Obesity results from the excessive accumulation of fat and its risk is not confined to adults; it extends also to children and adolescents (Knopp et al., 2008; Prokesch et al., 2009). Obesity is a multifactorial abnormality that 
has genetic and environmental bases. Changes in the environment interact with the other factors in a lethal combination. The genetic background loads the gun, but the environment pulls the trigger (Bray, 2004; Candib, 2007).

\section{Complications of obesity:}

Obesity, particularly abdominal obesity, has many complications such as dyslipidemia, atherosclerosis and type 2 diabetes mellitus (T2DM). Abdominal obesity is a major cause of cardiovascular disease (CVD) morbidity and mortality (Fig. 1) (Despres et al., 2008).

\section{1- Dyslipidemia :}

Obesity is a known complication of obesity (Sowers, 2003). Obese children and adults, particularly those with a central or abdominal distribution of fat, have elevated concentrations of serum triacylglycerol (TAG), a surrogate measure of very low density lipoprotein cholesterol (VLDLC) and low concentrations of high density lipoprotein cholesterol (HDL-C) (Abate, 1999; Freedman et al., 2002). Obesity is also associated with higher levels of total cholesterol (TC) and low density lipoprotein cholesterol (LDL-C) (Knopp et al., 2008).

\section{2- Oxidative stress :}

Obesity may be a state of chronic oxidative stress. It enhances oxidative stress in young and old population as shown by elevations in lipid peroxidation, or protein oxidation. Lipid peroxidation is associated with several indices of adiposity and a low systemic antioxidant defense (i.e. antioxidant enzymes, glutathione "GSH"). Oxidative stress is related to chronic disease and is one of the mechanisms underlying the development of co-morbidities (Vincent et al., 2007). It plays a role in the initiation of inflammation and development of insulin resistance (Wellen and Hotamisligil, 2005; Tilg and Moschen, 2008).

\section{3- Inflammation :}

In the liver and adipose tissues obesity promotes a state of chronic low-grade inflammation (Shoelson et al., 2007). Obesity-induced Inflammation results in increased infiltration of macrophages and release of cytokines like tumor necrosis factor-alpha (TNF$\alpha$ ), interleukin-6 (L-6), and interleukin-1beta (IL$1 \beta)$ and contributes significantly to insulin resistance (Cinti et al., 2005; Gonzalez-Gay et al.,
2006; Larsen et al., 2007).

\section{4- Insulin resistance, hyperinsulinemia and hyperglycemia:}

Insulin resistance (IR) hyperinsulinemia and hyperglycemia are linked with obesity (Sowers, 2003). Insulin resistance, which can be defined as a diminished ability of the cell to respond to the action of insulin, is the most important pathophysiological feature in many prediabetic states and is the first detectable defect in T2DM. It is usually compensated by hyperinsulinemia (Nieto-Vazquez et al., 2008). Although the pancreas manufactures extra insulin, it is not enough to counter the hyperglycemia, thus explaining the paradox of fasting hyperglycemia despite increased plasma insulin levels, which is known as IR (Gadde and Allison, 2006; Aguilera et al., 2008).

Alteration of glucose homeostasis is caused by faulty signal ttansduction via the insulin signaling proteins, which results in decreased glucose uptake by the muscle, altered lipogenesis and increased glucose output by the liver. This etiology may be related to a chronic inflammatory state (Martyn et al., 2008).

Although the classic features of acute inflammation are absent, signs of chronic inflammation are observed with the release of inflammatory cytokines including TNF- $\alpha$, IL-6 and IL-1 $\beta$. These cytokines have been implicated in the pathogenesis of IR (Hotamisligil, 2006; Shoelson et al., 2007). Obesity-associated adipocyte apoptosis (cell death) appears to be the primary event underlying insulin insensitivity. The subsequent infiltration of macrophages and release of reactive oxygen species (ROS) play an important role in cytokine-related IR (Fig. 2) (Cinti et al., 2005; Houstis et al., 2006).

The intracellular mediators of this inflammatory response include nuclear factor kappa $\mathrm{B}$ (NF$\mathrm{kB}$ ), c-Jun amino-terminal kinase-stress-activated protein kinase, and induction of the suppressor of cytokine signaling-3 (Kahn et al., 2006). Macrophage infiltration occurs not only in the adipocyte, but also in the liver. The associated activation of the c-Jun amino-terminal kinasestress-activated protein kinase pathway also promotes the development of hepatic inflammation leading to hepatic steatosis (fat deposition), lipid peroxidation and hepatic 
Rec. Pharm. Biomed. Sci. 3(2), 43- 59, 2019

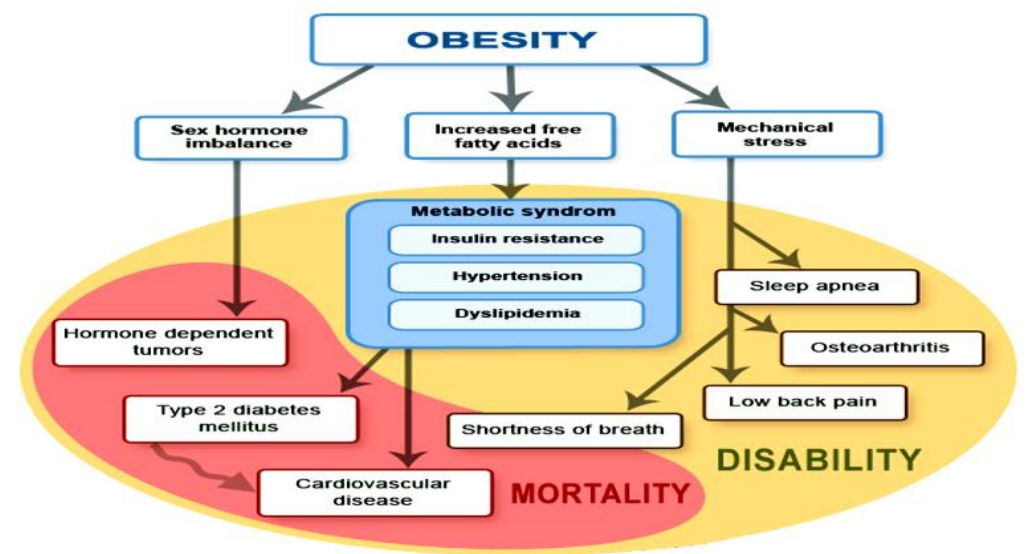

Fig. (1) : Complications of obesity (Knopp et al., 2008)

apoptosis, all of which are recognized in obese diabetics (Schattenber et al., 2006). Other etiologic factors have been proposed in the pathogenesis of obesity-induced IR. These factors include mitochondrial dysfunction, intracellular lipid accumulation in skeletal muscle and liver and decreased $\beta$-oxidation. Recent studies have elucidated that these pathologic and etiologic factors converge to activate inflammatory or stress signaling pathways (Abdul-Ghani and De Fronzo, 2008).

As shown in Figure (2), obesity leads to an inflammatory response in the liver and in adipose tissues. Obesity-induced inflammation results in infiltration of macrophages and release of cytokines, TNF- $\alpha$, IL- 6 and IL-1 $\beta$. The downstream effector of cytokine-induced inflammation is induction of inducible nitric oxide synthase (iNOS). The extremely high levels of nitric oxide (NO) that are released, together with reactive oxygen species, generate reactive nitrogen species including peroxynitrite, which leads to S-nitrosylation and tyrosine nitration (posttranslational modifications) of proteins which alters the function of many proteins, including those involved in insulin signaling.

\section{5- Type 2 diabetes :}

A major complication of obesity is type 2 diabetes (Keller, 2006; Martyn et al., 2008). Microvascular and macrovascular complications of diabetes, include stroke, coronary artery disease, peripheral vascular disease, retinopathy, and nephropathy (ElAtat et al., 2004).

\section{6- Metabolic syndrome :}

Overweight and obesity are associated with the metabolic syndrome (Cannon, 2007). The metabolic syndrome is the name for a clustering of risk factors for CVD and T2DM that are of metabolic origin. These include central obesity, elevated plasma glucose, high blood pressure, atherogenic dyslipidemia, a prothrombotic state, and a proinflammatory state (Aguilera et al., 2008; Milionis et al., 2008).

\section{Insulin in the brain :}

Glucose uptake by the brain and across the central nervous system and the blood brain barrier (BBB) takes place by saturable facilitated diffusion system. This occurs via an insulin independent manner through non-insulin sensitive glucose transporters; GLUT-1, GLUT3 , and GLUT-5 found in astrocytes, neurons and microglia, respectively. Hence, the brain was previously considered an insulin insensitive organ. However, several insulin sensitive glucose transporters as GLUT-2, GLUT-4 and GLUT-8 and insulin receptors (IRs) were found in the brain, which provide evidence that insulin must have other actions in the brain (Banks et al., 2012). One of the first recognized central insulin actions was its anorexic effect and its ability to reduce body weight gain through facilitating brain energy supply. It increases adenosine triphosphate (ATP) and consequently close ATPsensitive $\mathrm{K}^{+}$channels which in-turn reduce food intake. Additionally, insulin exerts its action by regulating neuronal activity in the hypothalamus and deactivating appetite centres (Morton et al., 2006; Jauch-Chara et al., 2012). Furthermore, insulin was found to stimulate the release of gonadotropin and luteinizing releasing hormones and thus insulin is involved in the central regulation of reproductive function (Bruning et al., 2000). 


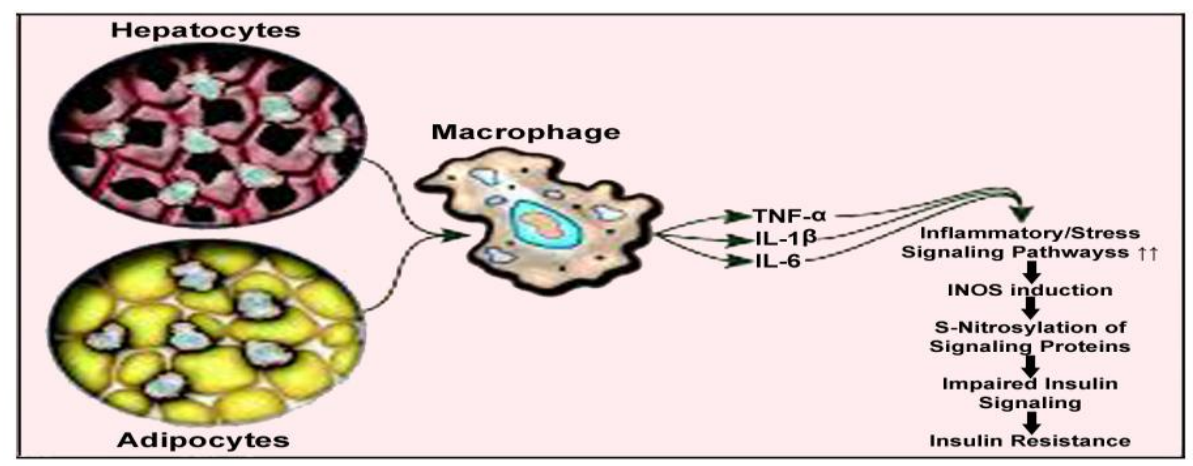

Fig. (2) : Pathogenesis of insulin resistance and hyperglycemia in obesity (Martyn et al., 2008)

Several lines of evidence have linked insulin and brain insulin signaling to improved cognition and memory. Number of molecular mechanisms have been involved, first, insulin has direct effect on neurotransmission, where its catabolic effect on glucose results in the production of numerous compounds e.g. acetyl CoA, glutamate and ATP. Acetyl CoA is involved in Ach synthesis. The latter along with glutamate are neurotransmitters involved in maintaining behaviour, memory and learning. Additionally, the produced ATP is required for preserving membrane stability, protein synthesis and synaptic transmission (Schulingkamp et al., 2000). Second, insulin enhances synaptic transmission and synaptic plasticity by inducing LTP, a mechanism that underlies some forms of learning and memory, through surface expression of $\mathrm{N}$-methyl-D-aspartic acid (NMDA) receptors and the glutamate receptor 1 subunit of amino-3hydroxy-5-methyl-4-isoxazole-propionic acid (AMPA) (Rani et al., 2016). Finally, it has been proved that insulin modulate tau phosphorylation, amyloid precursor protein (APP) expression and help in $A \beta$ clearance (Chen et al., 2014).

Insulin in the brain could be of peripheral origin, where insulin in the blood crosses BBB through insulin-binding sites in the brain endothelial cells of the BBB. These binding sites appear to either act as transporters of insulin or as classic receptors. Both affect the function of the barrier cell by activating intracellular machinery and mediating the effects of insulin on these cells. Moreover, insulin could be of central origin, where it could be synthesized in the brain (Blazques et al., 2014).

\section{Brain insulin signaling :}

Insulin receptors (IRs) have been proved to be widely expressed in discrete positions of the brain, located on both astrocytes and neurons. The highest distribution is found in cerebral cortex, hippo- campus, olfactory bulb, cerebellum, hypothalamus and choroids plexus (Duarte et al., 2012).

As in peripheral tissues, binding of insulin/insulin growth factor (IGF 1 or 2) ligands to tyrosine kinase receptors (IRs or IGF receptors) induces dimerization, trans autophosphorylation and activation of their tyrosine kinase domain that binds and activates IRS proteins. Subsequently, the two major downstream signaling cascades, PI3K/ AKT and the mitogen-activated protein kinase/extracellular signal regulated kinase (MAPK/ERK) pathways, are activated (Diehl et al., 2016). These were summarized in figure (3) (Chiu and Cline, 2010).

The first insulin/IGF signaling pathway (Fig. 4) (Blazquez et al., 2014), involves the activation of PI3K/AKT pathway in a mechanism by which the IRs proteins activates PI3K, that subsequently generates phosphatidyl inositol 3,4,5-triphosphate (PIP3). The latter activates phosphoinositide-dependent protein kinase-1 and hence, activation of AKT and its targets (Akintola and van Heemst, 2015).

\section{Targets of AKT include :}

1- AKT substrate of $160 \mathrm{kDa}(\mathrm{AS160})$ : once phosphorylated by AKT it is activated and causes translocation of the glucose transporter GLUT-4 to the plasma membrane (Takei and Nawa, 2014).

2- Mammalian target of rapamycin complex 1 (mTORC1) mediated protein : which has beneficial role in synaptic activity, dendritic growth of neurons, axon elongation and neuronal synaptic repair. However, its dysregulation causes detrimental effects including neurodegenerative diseases and neuronal cell 
Rec. Pharm. Biomed. Sci. 3(2), 43- 59, 2019

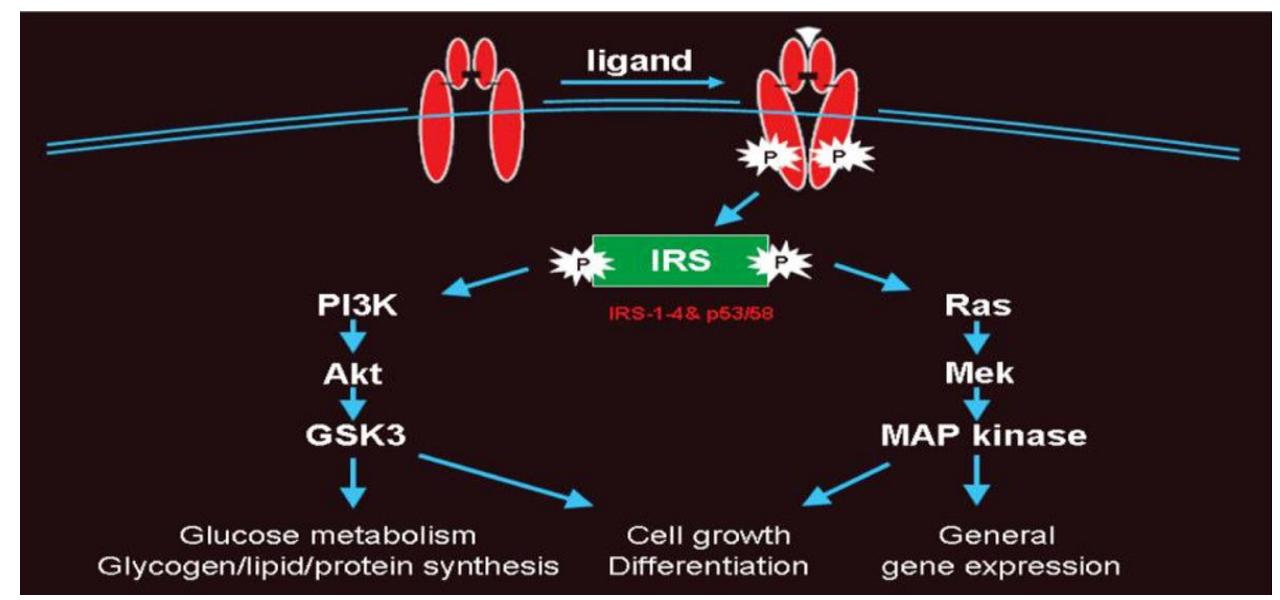

Fig. (3) : Insulin receptor signaling (Chiu and Cline, 2010)

death due to disrupted mTORC1-dependent autophagy, a major mechanism to degrade misfolded proteins and damaged organelles in neurons (Takei and Nawa, 2014).

3- Glycogen synthase kinase 3 (GSK3) : a serine/threonine kinase that regulates glycogen synthesis and controls multiple cell signaling pathways. Its activation, however, can phosphorylate tau protein, a process involved in the pathogenesis of $\mathrm{AD}$. AKT interferes the latter process via inactivating GSK3 $\beta$ (Kleinridders et al., 2014).

4- Fork head transcription factors (FOXOs) : where the activation of AKT promotes the phosphorylation and the inhibition of FOXO and hence protects the brain against apoptosis induced by apoptosis-stimulating fragment ligand (FasL) promoter and Bcl-2 interacting mediator of death (Bim); the targets of FOXO (Bassil et al., 2014).

The second major insulin/IGF signaling pathway (Fig. 4) (Blazquez et al., 2014), involves activation of MAPK/ERK pathway. Here, the phosphorylated IR/IGFIR and IRs proteins binds the SH2 domain containing adapter molecules (growth factor receptor-bound protein 2 "Grb2" and Sre Homology 2 domain). Grb2 then binds to son-of-sevenless (SOS), this complex then converts the inactive guanine nucleotide binding protein Ras to its active form by catalyzing the removal of guanosine diphosphate and binding of guanosine triphosphate. Activated Ras activates the protein kinase activity of rapidly accelerated fibrosarcoma (Raf) kinase, that subsequentally, phosphorylates and activates mitogen-activated protein kinase (MEK), MAPK, followed by phosphorylation of ERK1 and 2. This pathway thereby influences brain cell proliferation and differentiation and regulates cell survival (Blazquez et al., 2014). Consistently, a deficiency of ERK signaling in the brain causes neuronal death, demonstrating that this pathway is crucial for proper brain development (Klenridders, 2016).

\section{Defective insulin signaling in the brain :}

Defective insulin signaling in the brain contributes at the cellular level to the aggregation and deposition of $A \beta$ plaques, hyperphosphorylation of tau, promotion of neuroinflammation, disruption of synaptic plasticity and oxidative stress. These in turn cause impairment of memory and cognition (Craft et al., 2013). In other words, a neurodegenerative disorder in which defect in brain insulin signaling and consequently glucose metabolism lead to AD pathogenesis. Therefore, $\mathrm{AD}$ has been proposed as type 3 diabetes (Leszek et al., 2017).

\section{1- Amyloid plaques :}

The $A \beta$ plaques is one of the major hallmarks found in the brain of $\mathrm{AD}$ patients. These plaques are composed mainly of pathologically aggregated $A \beta$ peptides, predominantly $A \beta_{40}$ and $\mathrm{A} \beta_{42}$ derived from a larger molecule; APP. Normally, APP is cleaved within its extracellular domain to produce soluble APP alpha fragment by a protease known as $\alpha$-secretase. On the contrary, in $\mathrm{AD}$, proteolysis occurs by the sequential enzymatic actions of $\beta$-secretase, namely, BACE-1 to form APP beta. The carboxy terminal fragments (CTF) generated by $\alpha$ - and $\beta$ secretase are called (CTF83 and CTF99, 


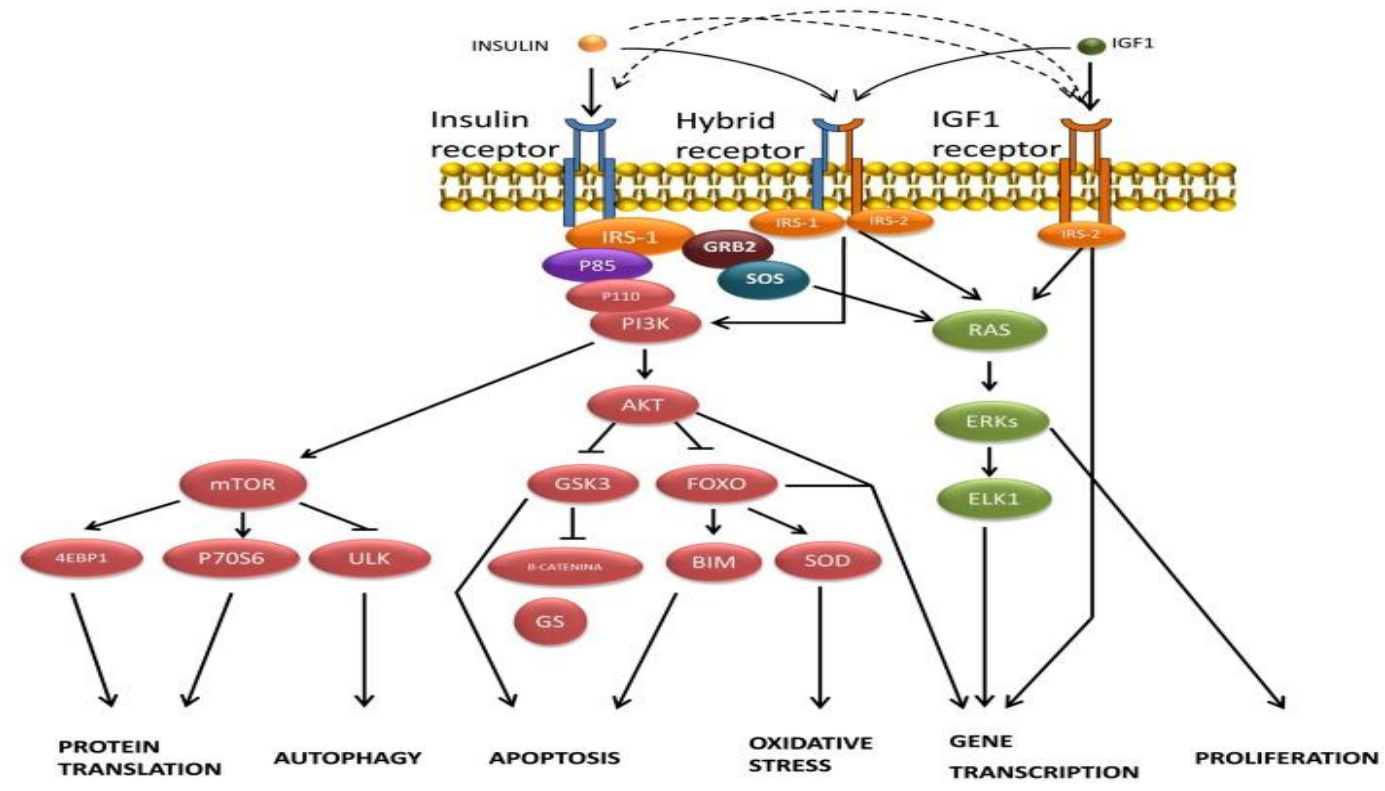

Fig. (4) : Insulin and insulin-like growth factor 1 receptors signaling pathways (Blazquez et al., 2014)

respectively. CTF83 and CTF99 are further cleaved by $\gamma$-secretase to produce $\mathrm{p} 3$ and $\mathrm{A} \beta$ (amyloidgenic pathway), respectively, as well as the aminoterminal APP intracellular domain (AICD) as shown in figure (5) (Thinakaran and Koo, 2008; Chow et al., 2010).

$\mathrm{A} \beta$ peptides are natural products of metabolism consisting of 36-43 amino acids. Monomers of $A \beta_{40}$ are much more prevalent than the aggregation-prone and damaging $A \beta_{42}$ species. An imbalance between production and clearance, and aggregation of peptides causes $A \beta$ accumulation the initiating factor in AD (Querfurth and La Ferla, 2010).

An exchangeable link was found between $A \beta$ aggregation and insulin signaling in the brain, where impaired insulin signaling causes $A \beta$ accumulation, while $A \beta$ oligomers induce insulin resistance in a vicious cycle (Fig. 6) (de la Monte, 2012). Insulin treatment elevates $S A P P \alpha$ secretion in a concentration and tyrosin kinase-dependent manner in the neuronal cells and thus promotes neuronal survival, neurite outgrowth, neural stem cell proliferation and enhances LTP. However, elevated insulin level in case of insulin resistance leads to $A \beta$ accumulation, as insulin and $A \beta$ complete for insulin degrading enzyme (IDE), an enzyme required for both insulin and $A \beta$ degradation in neurons and microglia (Rani et al., 2016). On the other hand, $A \beta$ oligomer induces loss of membrane IRs, elevation in proinflammatory tumor necrosis factor-alpha (TNF- $\alpha$ ) level and aberrant activation of c-Jun $\mathrm{N}$-terminal kinase (JNK) in neurons, which finally leads to abnormal serine phosphorylation of IRS-1. IRS-1 serine phosphorylation blocks the downstream insulin signaling. Abnormal insulin signaling accelerates plaque production in the brain by enhancing the amyloidogenic processing of the $\mathrm{A} \beta \mathrm{PP}$, and also increases $\mathrm{A} \beta$ aggregation and so on in an endless cycle (Beds et al., 2015).

\section{2- Hyperphosphorylation of Tau :}

Tau, is a microtubule associated protein, first discovered by Murray Weingarten, Marc Kirschner and their colleagues as a factor that was associated with tubulin promoting stabilization of axonal microtubules (Weingarten et al., 1975). Tau undergoes several post-translational modifications, including: O-GlcNAclation, phosphorylation, glycation, glycosylation, sumoylation and cleavage. O-GlcNAcylation is a dynamic modification involving the attachment of $\mathrm{N}$ acetyl-D-glucosamine (GlcNAc) moieties to the hydroxyl group of serine and threonine residues. Tau phosphorylation and dephosphorylation is mediated by several kinases and phosphatases including GSK3 $\beta$, CDK5, MAPK and protein phosphatase 2A (PP-2A) (Kim and Feldman, 2015).

Insulin resistance in the brain can induce different pathological tau modification (Fig. 7) (de la Monte, 2012) including tau hyperphos- 


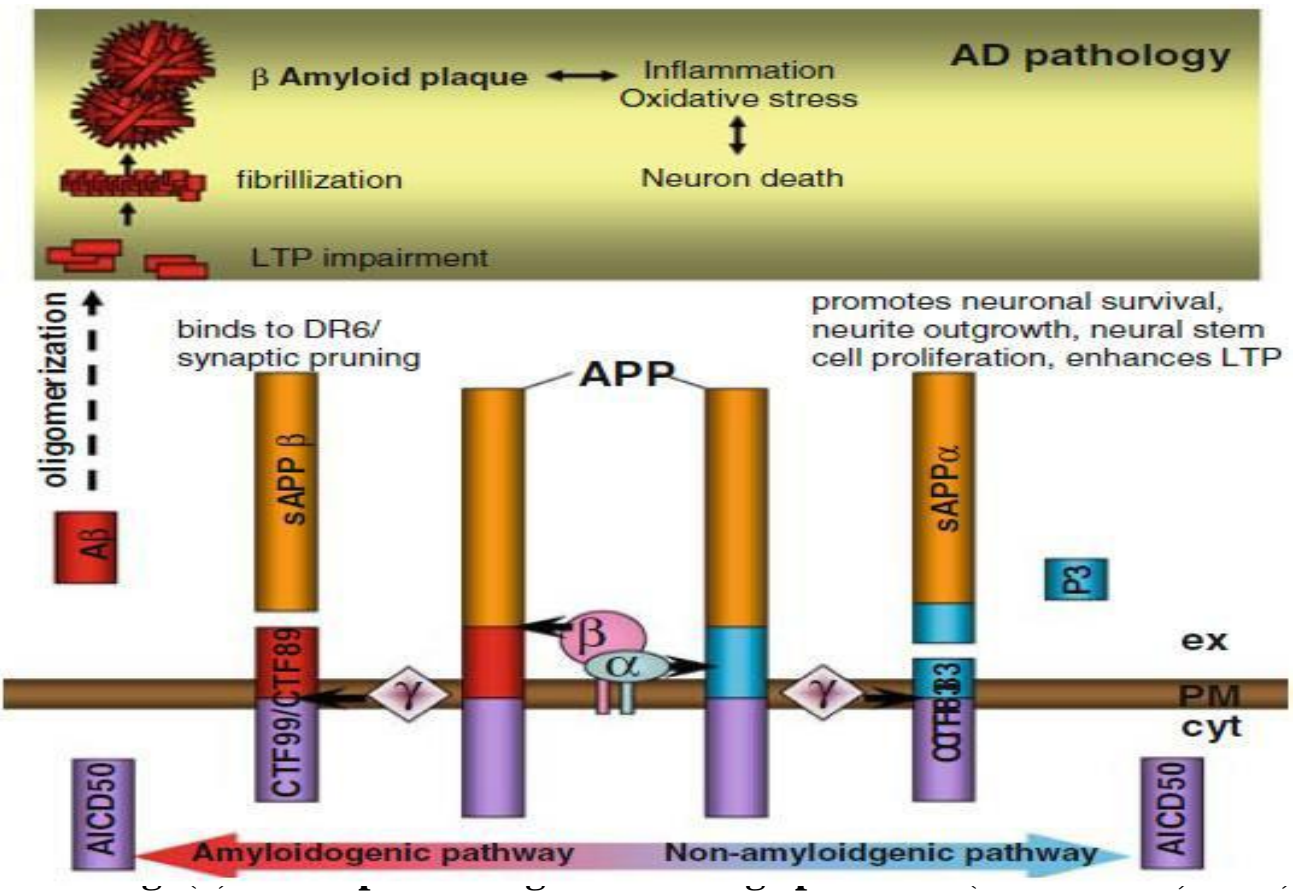

phorylation through preventing the stimulation of PI3K-AKT signaling resulting in GSK3 $\beta$ activation or dysregulation O-GlcNAcylation. Consequently, hyperphosphorylated tau misfolds and selfaggregates into insoluble fibrillar tangles of paired helical filaments and straight filaments. These disrupt microtubule organization and form NFT, dystrophic neuritis, and neuropil threads. In other words, the accumulation of fibrillar tau disrupts neuronal cytoskeletal networks and axonal transport, leading to synaptic disconnection and neurodegeneration (Iqbal et al., 2009). Furthermore, prefibrillar tau can aggregate into soluble neurotoxic oligomers that cause synaptic disconnection and neuronal death (Takashima, 2010).

\section{3- Neuroinflammation :}

One of the consequences of disrupted brain insulin signaling is a well defined state of neuroinflammation, represented by increased inflammatory cytokines, TNF- $\alpha$, and cyclooxygenase- 2 and decreased interleukin-10, as well as activated nuclear factor-kappB (NFkB) pathway, which further activates amyloid pathology. The aforementioned inflammatory state is a result of defect in IR/IRS-1/ AKT/GSK$3 \alpha / \beta$ signaling pathway and decreased IDE (A $\beta$ insulin degrading protease), that results in amyloid plaque formation. The formed amyloid peptides activates microglia and astrocytes by

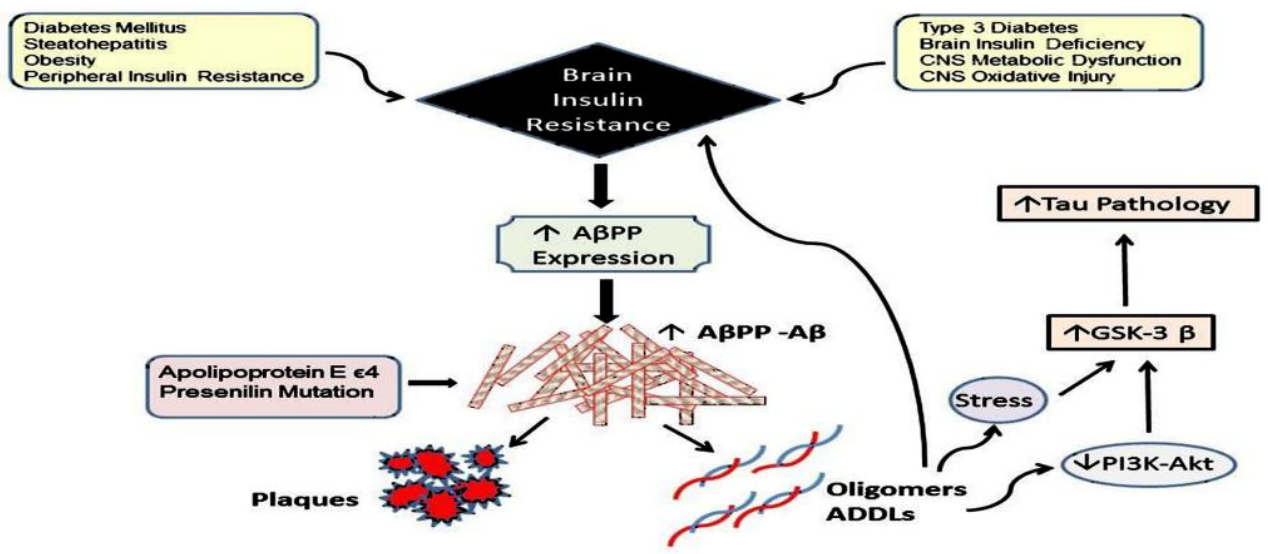

Fig. (6) : Brain insulin resistance and AßPP-Aß deposition (de la Monte, 2012) 


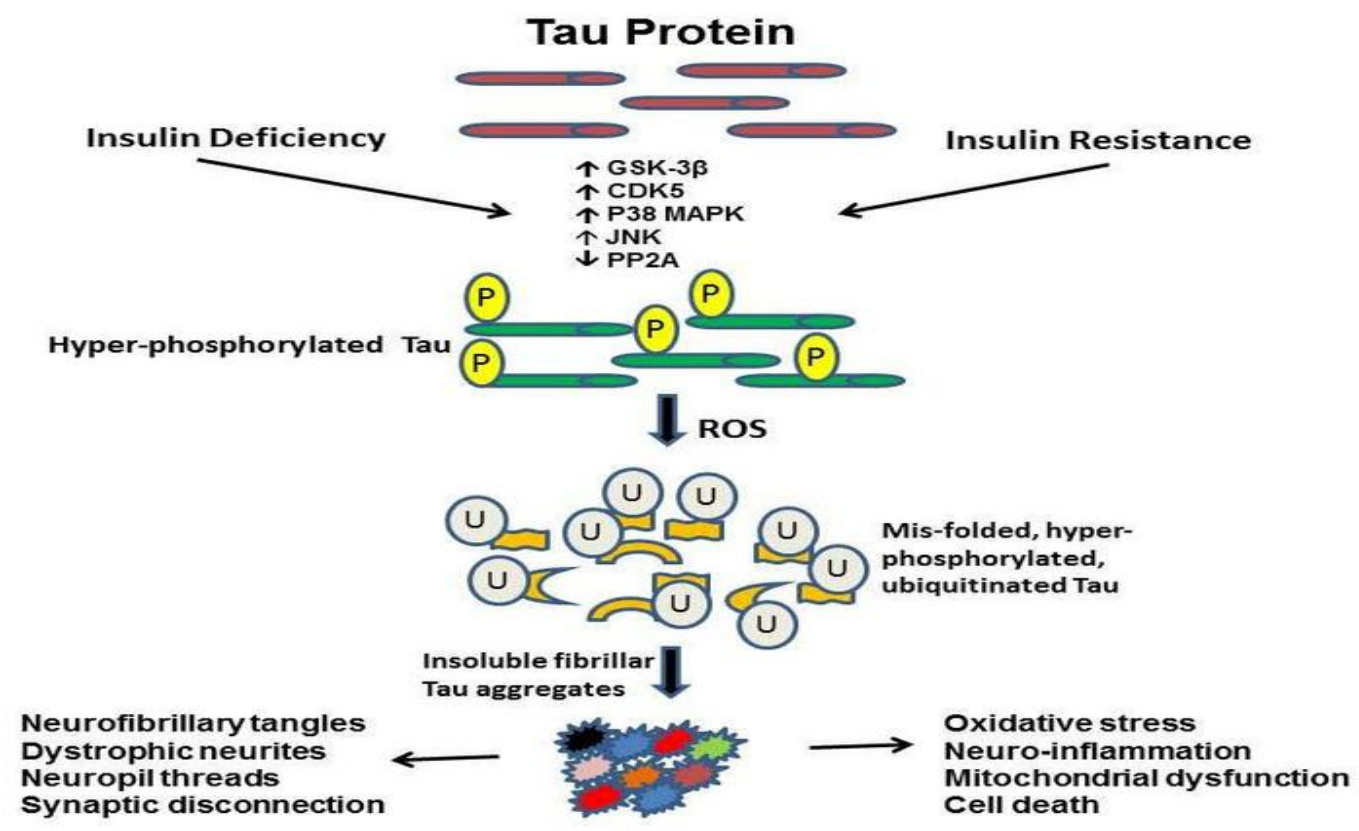

Fig. (7) : Role of brain insulin deficiency or resistance in Tau pathology (De la Monte, 2012)

binding to its pattern recognition receptors, and triggers the release of inflammatory cytokines. Moreover, neuroinflammation is mediated by caspase-9, one of the main initiator caspases that activates the executioner caspase (caspase-3), which produce cell death in cortical and hippocampal neurons (Rajasekar et al., 2017).

\section{4- Disruption of synaptic plasticity and transmission :}

Defective insulin signaling contributes to deficit in neuro-plasticity, namely, decreased neuronal spine density, decreased synaptic transmission and increased oxidative stress (Grillo et al., 2015). Several findings support the role of insulin signaling in recruiting the machinery necessary for both excitatory and inhibitory neurotransmission. For excitatory receptors, insulin modifies the endocytosis of AMPA receptor, which may lead to long-term depression of excitatory synaptic transmission in the hippocampus and cerebellum. Moreover, insulin promotes the delivery of NMDA receptors to the cell surface by exocytosis (Banks et al., 2012; Rani et al., 2016).

For inhibitory receptors, insulin promotes gamma amino butyric acid (GABA) receptor-mediated synaptic transmission by the recruitment of GABA receptors to postsynaptic membranes. This confirms that impaired insulin signaling in brain causes disruption in synaptic function and plasticity
(Kandimalla et al., 2017).

\section{5- Oxidative stress and advanced glycation end products :}

Disrupted insulin signaling leads to mitochondrial dysfunction and consequently a well-defined state of oxidative stress. The latter involves the production of reactive oxygen species (ROS) and reactive nitrogen species, such as superoxide anion, hydrogen peroxide $\left(\mathrm{H}_{2} \mathrm{O}_{2}\right)$, hydroxyl radical, nitric oxide, and the related peroxynitrite, as well as, lipid peroxidation. Eventually, oxidative damage is associated with the pathophysiology of many diseases through inducing severe damage to cell membranes, and breakdown of deoxyribonucleic acid (DNA) and protein structures. It can also develop a state of chronic inflammation and cause cell apoptosis through modulating the activity of some transcriptional factors as NF- $\mathrm{\kappa B}$. As a result of these changes in the brain, cerebral glucose metabolism is reduced leading to reduced ATP synthesis, contributing to disruption of neuronal functioning, loss of synapses, and overall neurodegeneration (Fig. 8) (Chen et al., 2014; Verdile et al., 2015).

Additionally, the over production of ROS results in the glycation of proteins and the production of advanced glycation end products (AGEs), that have pro-oxidant effect. Receptor for advanced 


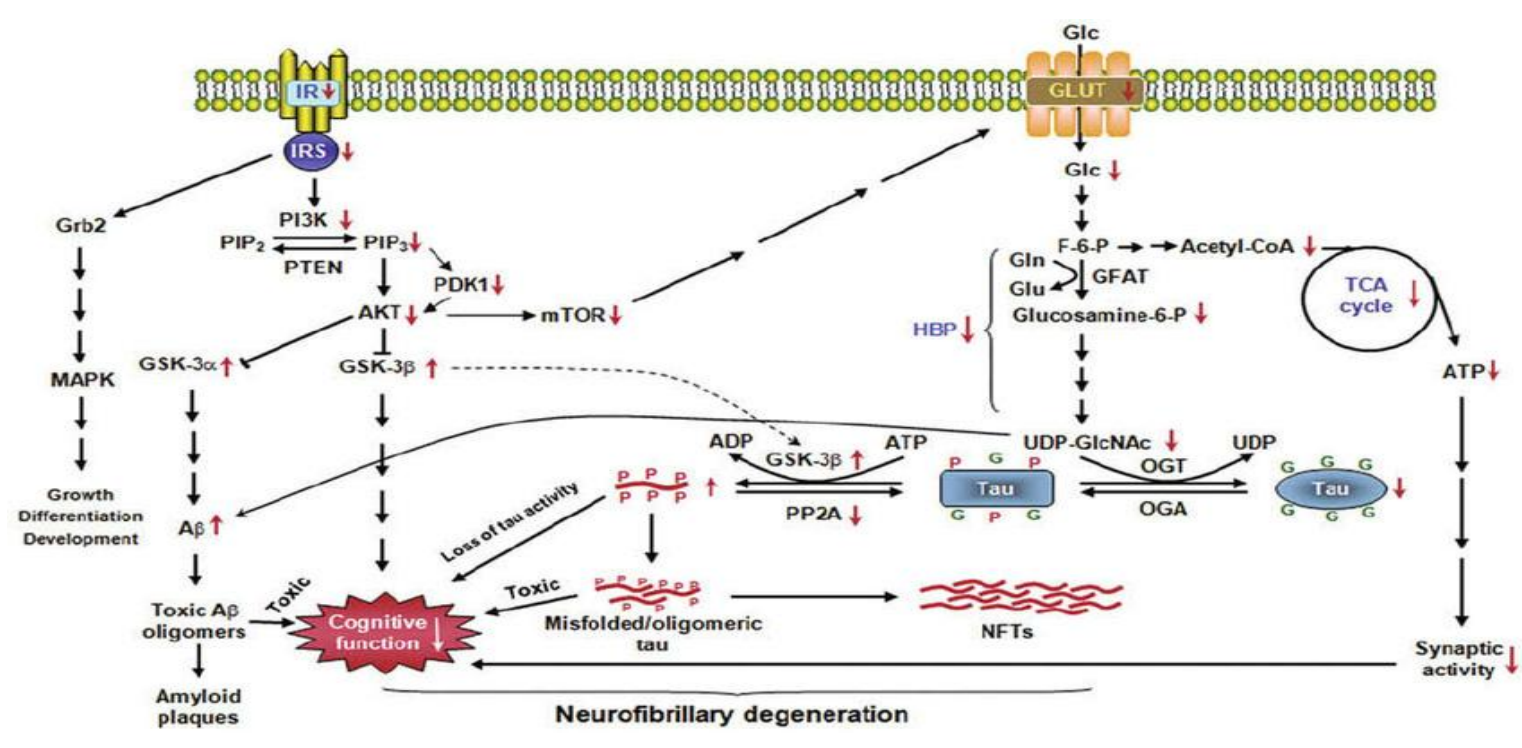

Fig. (8): Possible mechanisms by which deficient brain insulin signaling contributes to AD (Chen et al., 2014)

glycation end products (RAGE) activation, along with cerebral accumulation of AGEs as a key mediator, interfere with cell functions through the development of mitochondrial dysfunction, oxidative stress, and inflammatory reaction. RAGE also contributes to neurodegenerative diseases by acting as a ligand for $A \beta$ fibrils and may be involved in the neurotoxic effects of $A \beta$ in neurons and microglia. Furthermore, RAGE upregulates the accumulation and transport of $\mathrm{A} \beta$ across the $\mathrm{BBB}$ (Jayaraman and Pike, 2014).

\section{Alzheimer's disease:}

Alzheimer's disease (AD) was first described by Alois Alzheimer in 1907 (Sastre et al., 2008). It is the most common form of dementia, accounting for $70 \%-90 \%$ of all cases (Ritchie and Lovestone, 2002; Luchsinger, 2008). The social and economic consequences of this neurodegenerative disease represent a significant challenge to society and it is imperative that strategies to prevent or delay the onset of AD are developed (Shagam, 2009).

Alzheimer's disease is characterized by decline in at least two of four essential cognitive functions : (1) memory; (2) ability to speak or understand language; (3) capacity to plan, make sound judgements, and carry out complex tasks and (4) ability to process and interpret visual information. The decline may be severe enough to interfere with day-to-day life (Kidd, 2008). Pathologically, amyloid plaques and neurofibrillary tangles are hallmarks of AD. Amyloid plaques are aggregates of beta-amyloid $(A \beta)$, a protein derived from a larger protein called amyloid protein precursor (APP) (Van der Anwera et al., 2005). Amyloid deposits within and around blood vessels and intracellular neurofibrillary tangles are characteristics of AD brain pathology and other neurological disorders (Bergamaschini et al., 2009)

There are several links between obesity and AD such as oxidative stress, inflammation and the other complications of obesity like dyslipidemia, insulin resistance, diabetes, hypertension, metabolic syndrome, heart disease and cerebrovascular disease (Fig. 9) (Luchsinger, 2008)

Alzheimer's disease patients exhibited increased oxidative stress markers and abnormally poor antioxidant status compared to healthy controls (van Rensburg et al., 2006; Kidd, 2008). Since obesity is a state of chronic oxidative stress, it's considered as one of the links between obesity and AD progression (Vincent et al., 2007).

High cholesterol and LDL-c levels and lower plasma HDL-c are important risk factors for AD. Similarly, serum apo A1 levels have been shown to be markedly lower in AD patients and highly correlated with AD cognitive decline (Kuo et al., 1998; Merched et al., 2000; Martins et al., 2006). 


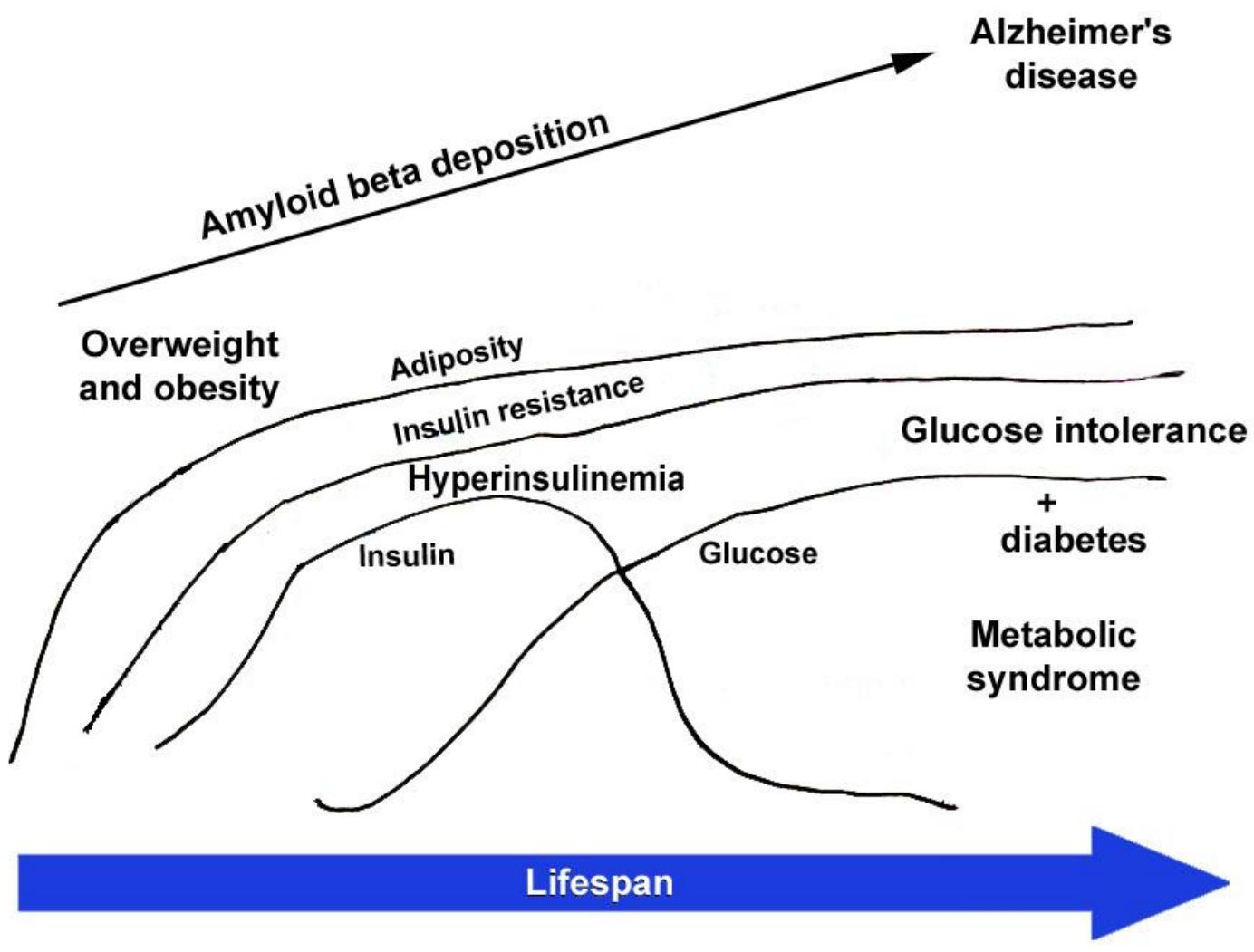

Fig. (9) : Natural history of the continuum of obesity, insulin resistance, hyperinsulinemia, glucose intolerance and diabetes (Luchsinger, 2008)

Several studies show an association between hyperinsulinemia and an increased risk of $\mathrm{AD}$ (Peila et al., 2004). These studies also found that the risk of $\mathrm{AD}$ related to hyperinsulinemia was higher among persons with the apoE- $\varepsilon 4$. Borderline diabetes and impaired glucose tolerance are linked to an increased risk of dementia and AD (Qiu et al., 2007; Xu et al., 2007). This association may reflect a direct effect of hyperglycemia, hyperinsulinemia, and diabetes-related comorbidities such as hypertension and dyslipidemia on brain degenerative changes (Fig. 10) (Biessels et al., 2006; Korf et al., 2006). Furthermore; cardiovascular disease was found to be associated with increased risk of $\mathrm{AD}$, especially in people with peripheral arterial disease, suggesting that extensive peripheral atherosclerosis is a risk factor for $\mathrm{AD}$ (Hofman et al., 2006). Purandare et al. (2006) added that cerebrovascular disease, stroke and spontaneous cerebral emboli were related to a higher risk of AD. Increased obesity causes IR and hyperinsulinemia. Insulin levels may decrease over time due to pancreatic failure, resulting in glucose intolerance and diabetes. Obesity hyperinsulinemia, glucose intolerance and diabetes could increase brain $A \beta$ deposition leading to $\mathrm{AD}$ individually or in aggregate in addition to causing cerebrovascular disease. Several studies have found that high physical activity is associated with low adiposity, lower hyperinsulinemia, and is inversely related to AD risk (Larson et al., 2006). Type 2 diabetes is nowadays strongly associated with $\mathrm{AD}$ to the extent that $\mathrm{AD}$ is termed type 3 diabetes.

Type 2 diabetes increases the risk of $\mathrm{AD}$ by approximately two folds through decreasing the clearance of $\mathrm{A} \beta$ by competing of insulin on IDE, also RAGE that play a role in the pathogenesis of diabetes, are present in cells associated with senile plaques and NFT (Mayeux and Stern, 2012), as shown in figure (11) (Kleinridders et al., 2014). 


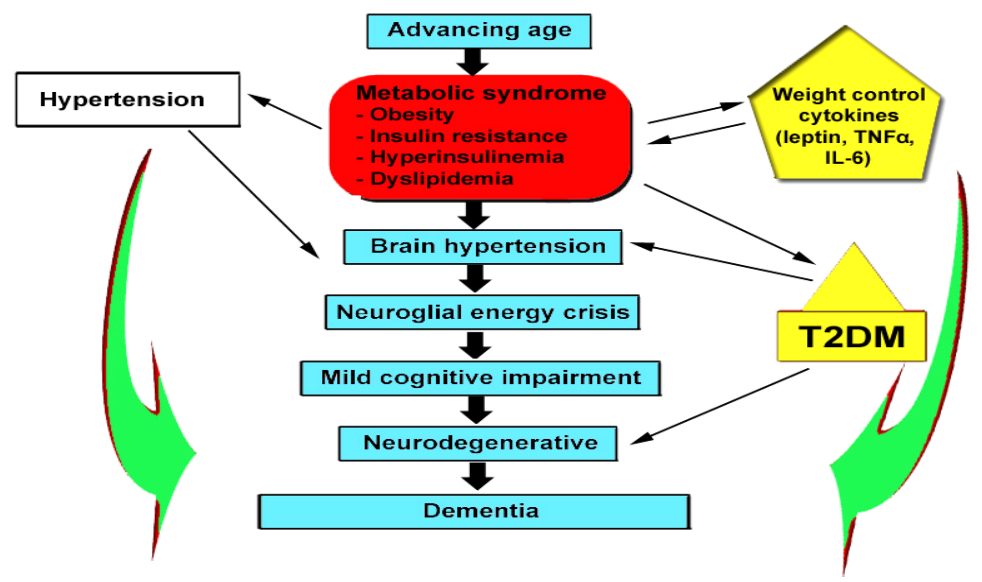

Fig. (10) : Potential relationships between components of the metabolic syndrome and the development of AD (Milionis et al., 2008)

\section{Management of AD :}

Understanding all the key players in $\mathrm{AD}$ neuropathogenesis will help identify possible therapeutic targets. Several hypotheses were proposed to explain $\mathrm{AD}$ pathogenesis on a molecular level (Wen et al., 2017).

\section{1- Cholinergic hypothesis :}

The earliest hypothesis explaining AD pathogenesis focused on cholinergic system, the major neurotransmitter system involved in learning and memory, and its deficit in early AD stages through loss of cholinergic neurons, reduced choline uptake and decreased Ach release (Contestabile, 2011).

The relation between cholinergic hypofunction and $\mathrm{AD}$ can be manifested in several forms. Deterioration of cholinergic neurons and loss of muscarinic and nicotinic receptors observed in $\mathrm{AD}$ lead to impaired release of neurotransmitters and cholinergic conduction. The latter plays a key role in the sleep-wake cycle, cerebral blood flow, proper cortical development, activity, learning, memory and cognition. Additionally altered cholinergic innervations and increased AchE accelerate the aggregation of $\mathrm{A} \beta$ and consequently plaque formation. Moreover, choline acetyltransferase that is greatly reduced in $\mathrm{AD}$ is correlated with the numbers of NET in AD (Ahmed et al., 2017). The proposed intervention for this hypothesis is using drugs that are classified as cholinesterase inhibitors to inhibit AchE and hence enhance cholinergic neurotransmission. AchE is an enzyme that breaks down Ach and other choline esters. It belongs to serine proteases family with the highest expression in the plasma, neuromuscular junctions and the nervous system. Only four AchE inhibitors namely donepesil, tacrine, galantamine and revastigmine are approved by the FDA (Islam and Taberz, 2017).

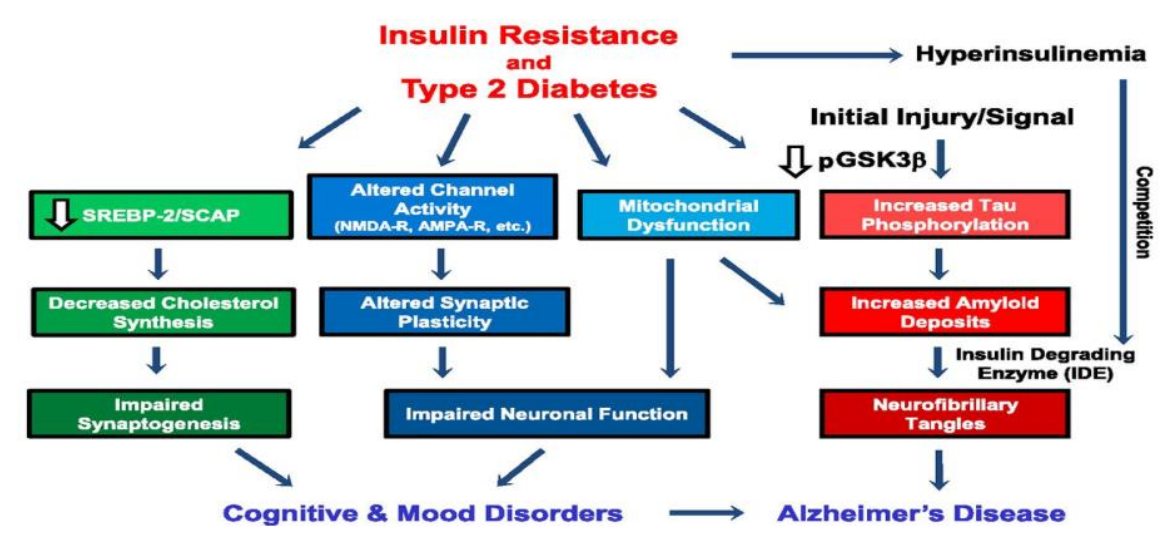

Fig. (11): Role of insulin resistance and type 2 diabetes in developing AD

(Kleinridders et al., 2014) 
Patients on AchE inhibitors suffers from gastrointestinal side effects as diarrhea, nausea, vomiting, anorexia and weight loss. In addition, AchE inhibitors is contraindicated in bradycardia as they are known to slow heart rate. Other observed side effects include urinary dysfunction, muscle cramps and abnormalities in dreaming. From the four approved drugs, tacrine is no longer used due to its hepatotoxicity (Aisen et al., 2012).

\section{2- Amyloid cascade hypothesis :}

Amyloidogenic cascade is an early feature of $\mathrm{AD}$ that in-turn drives tau hyperphosphorylation, NFT formation and neuron death. This cascade encounters an imbalance between increased toxic $\mathrm{A} \beta$ production by sequential $\beta$ - and $\gamma$-secretase cleavage and decreased clearance. So, clinical trials from the late 1990s onwards started to test the possibility of disrupting this cascade. Although the concept looks simple, the practice was much more complicated, as separate drug targets are required due to different sites of toxicity. Oligomers may be toxic at synapses, while $\mathrm{A} \beta$ fibrils may be proinflammatory and toxic in their local interstitial environment and so on (Schneider et al., 2014). Several anti-amyloid therapies have been proposed and studied including rosiglitazone, pioglitazone and semagacestat (Mangialasche et al., 2010).

\section{3- Tau hypothesis :}

The second major neuropathological feature that develops with the progression of $\mathrm{AD}$ is the accumulation of NFT. This processes starts with abnormal hyperphosphorylation of tau that sequesters normal tau, and the two major neuronal microtubule-associated protein (MAP1 and MAP2). This consequently disrupts microtubules and promotes self-assembly into tangles of paired helical and or straight filaments. GSK-3 $\beta$ and CDK5, two major kinases, are involved in hyperphosphorylation of tau are up-regulated in AD. However, PP-2A, the major phosphatase enzyme that regulate the phosphorylation of tau, is down-regulated. Therefore, one attractive approach in the treatment of $\mathrm{AD}$ could be targeting these enzymes by inhibition of GSK-3 $\beta$ activity and modulation of PP-2A. Lithium chloride, is prescribed as a GSK-3 $\beta$ inhibitor (Iqbal and Grundke-Iqbal, 2008).

Additionally, in a study by Li et al. (2004) in rat hippocampal slices that used okadaic acid to inhibit PP-2A activity, using memantine as a treatment restored PP-2A activity and hence inhibited hyper- phosphorylation of tau. However, memantine is a positively charged molecule and probably enters a neuron only during excitotoxicity when the NMDA receptor channels are open. Therefore, its therapeutic benefit might $b$ limited to only those patients and/or the advanced states of the disease when there is persistent excitotoxicity.

A set of existing research data suggested a tie between the phytochemical content of raspberries and antioxidant and antiproliferative (chemopreventive) effects in cell and rodent al studies (Gonzalez et 2009 ) Other results showed an anti-inflammatory effect of raspberry extract and or ellagic acid in a variety of models (Sangiovanni et al 2013) There are at least two reports of an effect of RK on vasorelaxation and blood pressure ( Jia et al 2011) The body of research from human studies is growing and suggests a role for red raspberries in reducing the risk of metabolic disease ( Burton et al 2016 ) Therefore, the aim of this study was to clarify the effect of RK with calorie restricted diet in obesity induced Alzheimer disease namely modulation of molecular pathway in oxidative stress, dyslipidemia, amyloid beta-peptide (AB) extracellular plaques formation and cholinergic activity using orlistate as reference antiobese drug.

\section{Conclusion:}

CR diet administration with RK effectively modulated the neurodegenerative changes induced by obesity to greater extend than its administration with orlistate due to antioxidant effect of RK. This was reflected on BACE-1 expression and subsequently the accumulation of $\mathrm{A} \beta$ plaques which is the hallmark of $\mathrm{AD}$. So this study supports the recent evidence suggesting the potential of RK supplement with CR diet as an effective intervention for prevention and treatment of $\mathrm{AD}$.

\section{References}

Abate N 1999: Obesity as a risk factor for cardiovascular disease. Am J Med; 107: 12S$13 \mathrm{~S}$.

Abdul-Ghani MA and De Fronzo RA 2008 : Mitochondrial dysfunction, insulin resistance and type 2 diabetes mellitus. Curr Diab Rep; $8: 173$ 178.

Afifi NA, Ramadan A, Erian EY et al. 2017: 
Trigonelline attenuates hepatic complications and molecular alterations in high fat high fructose diet induced insulin resistance in rats. Canadian Journal of Physiology and Pharmacology; 95: 427-436.

Ahmed T, Zahid S, Mahboob A et al. 2017 : Cholinergic system and post-translational modification : An insight on the role in Alzheimer's disease. Curr Neuropharmacol; 15: 480-494.

Aguilera CM, Gil-Campos M, Canete R et al. 2008 : Alteration in plasma and tissue lipids associated with obesity and metabolic syndrome. Clin Sci (Lond); 114 : 183-193.

Aisen PS, Cummings J and Schneider LS 2012: Symptomatic and nonamyloid/tau based pharmacologic treatment for Alzheimer disease. Cold Spring Harb Perspect Med; 2: a006395.

Akintola AA, von Heemst D 2015: Insulin, aging and the brain : mechanisms and implications. Front Endocrinol (Lausanne); $6: 13$.

Astrup A, Dyerberg J, Selleck M et al. 2008 : Nutrition transition and its relationship to the development of obesity and related chronic diseases. Obes Rev; 9 Suppl. $1:$ 48-52.

Banks WA, Owen JB and Erickson 2012 : Insulin in the brain : there and back again. Pharmacol Ther; $136: 1-18$.

Bassil F, Fernagut PO, Bezard E et al. 2014 : Insulin, IGF-1 and GLP-1 signaling in neurodegenerative disorders : targets for disease modification? Prog Neurobiol; 118: 1-18

Bedse G, Di Domenico F, Serviddio et al. 2015 : Aberrant insulin signaling in Alzheimer's disease : current knowledge. Front Neurosci; 9 : 204.

Bergamaschini L, Rossi E, Vergani et al. 2009 : Alzheimer's disease : Another target for heparin therapy. Scientific World Journal; 9 : 891-908.

Biessels GJ, Staekenborg S, Brunner E et al. 2006 : Risk of dementia in diabetes mellitus : A systematic review. Lancet Neurol; 5 : 64-74

Blazquez E, Velazquez E, Hurtado-Carniero V et al. 2014: Insulin in the brain : its pathophysiological implications for states related with central insulin resistance, type 2 diabetes and Alzheimer's disease. Front Endocrinol (Lausanne); $5: 161$.

Bray GA 2004 : The epidemic of obesity and changes in food intake : the Fluoride hypothesis. Physiol Behav; 82 : 115-121.

Bruning JC, Cautam D, Burks DJ et al. 2000 : Role of brain insulin receptor in control of body weight and reproduction. Science; 289 : 21222125 .

Burton-Freeman, BM. Sandhu, AK. Edirisnghe, I. 2016 Red raspberry and their bioactive polyphenols : Cardiometabolic and neuronal health link, Adv Nutr; 7(1) 44-65.

Caballero B 2005 : A nutrition paradoxunderweight and obesity in developing countries. N Engl J Med; 352 : 1514-1516.

Cameron AJ, Welborn TA, Zimmet PZ et al. 2003 : Overweight and obesity in Australia : the 1999-2000 Australian diabetes, obesity and lifestyle study (Aus Diab). Med J Aust; 178 : 427-432.

Candib LM 2007 : Obesity and diabetes in vulnerable populations : reflection on proximal and distal causes. Ann Fam Med; 5 : 547-556

Cannon CP 2007 : Cardiovascular disease and modifiable cardiometabolic risk factors. Clin Cornerstone; $8: 11-28$.

Chen Y, Deng Y, Zhang B et al. 2014 : Deregulation of brain insulin signaling in Alzheimer's disease. Neurosci Bull; 30 : 282-294

Chiu SL and Cline HT (2010) : Insulin receptor signaling in the development of neuronal structure and function. Neurol Dev; $5: 7$.

Chow VW, Mattson MP, Wong PC et al. 2010 : An overview of App processing enzymes and products. Neuromolecular Med; $12: 1-12$.

Cinti S, Mitchell G, Barbatelli G et al. 2005: Adipocyte death defines macrophage localization and function in adipose tissue of obese mice and humans. J Lipid Res; 46 : 2347-2355.

Contestabile A 2011 : the history of the cholinergic hypothesis. Behav Brain Res; 221 : 334-340.

Craft S, Cholerton B, Baker LD 2013 : Insulin and Alzheimer's disease : untangling the web. J Alzheimers Dis; 33 Suppl. 1 : S263-275.

Cuevas A, Alvarez V and Olivos C2009: The 
emerging obesity problem in Latin America Expert. Rev Cardiovasc Ther; $7: 281-288$.

De La Monte SM 2012 : Brain insulin resistance and deficiency as therapeutic targets in Alzheimer's disease. Curr Alzheimer Res; 9: 35-66.

Deng XL, Liu Z, Wang C et al. (2017: Insulin resistance in ischemic stroke. Metab Brain Dis; 32 : 1323-1334.

Despress JP, Arsenault BJ, Cote M et al. 2008 : Abdominal obesity: the cholesterol of the 21st century ? Can J Cardiol; 24 Suppl. D : 7D-12D.

Diehl T, Mullins R and Kapogiannis D 2016 : Insulin resistance in Alzheimer's disease. Transl Res; $183: 26-40$.

Duarte AI, Moreira PI and Olivira Cr 2012 : Insulin in central nervous system more than just a peripheral hormone. J Aging Res; 384017.

El-Atat F, Mc Farlane SI and Sower JR 2004 : Diabetes, hypertension and cardiovascular derangements : pathophysiology and management. Curr Hypertens Rep; 6 : 215-223.

Freedman DS, Bowman BA, Otvos JD et al. 2002 : Difference in the relation of obesity to serum triacylglycerol and VLDL subclass concentration between black and white children : the Bogalusa heart study. Am J Clin Nutri; 75 : 827-833.

Gadde KM and Allison DB 2006 : Cannabinoid-1 receptor antagonist, rimonabant, for management of obesity and related risks. Circulation; 114 : 974-984

Gonzalez-Gay MA, De Matias JM, GonzalezJuanatey $\mathrm{C}$ et al. 2006: Anti-tumor necrosis factoralpha blockade improves insulin resistance in patients with rheumatoid arthritis. Clin Exp Rheumatol; 24 : 83-86.

Gonzalez-Sarrias, A. Espin, JC. Temas-Barberan, FA. 2009 Gene expression cell cycle arrest and MAPK signaling regulation in Caco 2 cell exposed to ellagic acid and its metabolites, urolithins. Mol Nutr Food Res; 53(6) 686-698.

Grillo CA, Piroli GG, Lawrence RC et al. 2015 : Hippocampal insulin resistance impairs spatial learning and snaptic plasticity. Diabetes; 64 : 3927 3936.

Hofman A, de Jong PT, van Duijn CM et al. 2006 : Epidemiology of neurological diseases in elderly people : What did we learn from the Rotterdam study ? Lancet Neurol; 5: 545-550

Hotamisligil GS 2006 : Inflammation and metabolic disorders. Nature; 444 : 860-867.

Houstis N, Rosen ED and Lander ES 2006 : Reactive oxygen species have a causal role in multiple forms of insulin resistance. Nature; 440 : 944-948.

Islam BU and Tabrez S 2017 : Management of Alzheimer's disease: An insight of the enzymatic and other novel potential targets. Int $\mathrm{J}$ Biol Macromol; 97 : 700-709.

Iqbal K, Liu F, Gong CX et al. 2009 : Mechanisms of tau-induced neurodegeneration. Acta Neuropathol; 118 : 53-69

Iqbal K and Grundke-Iqbal I 2008 : Alzheimer neurofibrillary degeneration : significance, etiopathogenesis, therapeutics and prevention. $\mathbf{J}$ Cell Mol Med; 12 : 28-55.

Jauch-Chara K, Friedrich A, Rezmer M et al. 2012: Intranasal insulin suppresses food intake via enhancement of brain energy levels in humans. Diabetes; 61 : 2261-2268.

Jayaraman A and Pike CJ 2014 : Alzheimer's disease and type 2 diabetes : multiple mechanisms contribute to interactions. Curr Diab Rep; 14 : 476

Jebb S 2004 : Obesity : causes and consequences. Women's Health Medicine; 1 : 38-41.

Jia, H. Liu, JW. Ufur, H. 2011 The antihypertensive effect of ethyacetate extract from red raspberry fruit in hypertensive rats, Pharmacogn Mag; 7(25) 19.

Kahn SE, Hull RL and Utzschneider KM 2006 : Mechanisms linking obesity to insulin resistance and type 2 diabetes. Nature; 840-846.

Kandimalla R, Thirumala Y and Reddy PH2017 : Is Alzheimer's disease a type 3 diabetes ? A critical appraisal. Biochimica et Biophysica Acta Molecular Basis of Disease; 1863 : 1078-1089.

Keller U 2006 : From obesity to diabetes. Int J Vitam Nutr Res; 76 : 172-177.

Kidd PM 2008 : Alzheimer's disease, amnestic, mild cognitive impairment and age-associated memory impairment : current understanding and 
progress toward integrative prevention. Altern Med Rev; $13: 85-115$.

Kim B and Feldman EL 2015 : Insulin resistance as a key link for the increased risk of cognitive impairment in the metabolic syndrome. Exp Mol Med; 47 : e149.

Kleinridders A, Ferris HA, Cai W et al. 2014 : Insulin action in brain regulates systemic metabolism and brain function. Diabetes; 63 : 22322243

Kleinridders A 2016 : Deciphering brain insulin receptor and insulin-like growth factor 1 receptors signaling. J Neuro-endocrinol; 28.

Knopp RH, Paramsothy P, Atkinson B et al. 2008 : Comprehensive lipid management versus aggressive low-density lipoprotein lowering to reduce cardiovascular risk. Am J Cardiol; 101 : 48B-57B.

Korf ES, White LR, Scheltens P et al. (2006) : Brain aging in very old men with type 2 diabetes: The Honolulu-Asia Aging study. Diabetes Care; 29 : 2268-2274.

Kuo YM, Emmerling MR, Bisgaier C et al. 1998: Elevated low density lipoprotein in Alzheimer's disease correlates with brain a beta 1-42 levels. Biochem Biophys Res Commun; 252 : 711-715.

Larsen CM, Faulenbach M, Vaag A et al. (2007): Interleukin-1 receptor antagonist in type 2 diabetes mellitus. N Engl J Med; 356 : 1517-1526

Larson EB, Wang L, Bowen JD et al. 2006: Exercise is associated with reduced risk for incident dementia among persons 65 years of age and older. Ann Intern Med; 144 : 73-81

Leszek J, Trypka E, Tarasov VV et al. 2017: Type 3 diabetes mellitus : A noval implication of Alzheimer disease. Curr Top Med Chem; 17 : 13311335

Levitt NS and Lambeert EV (2003): The foetal origins of the metabolic syndrome - a South African perspective. Cardiovasc J S Afr; 13 : 179180.

Li L, Sengupta A, Haque N et al. 2004: Memantine inhibits and reverse the Alzheimer type abnormal hyper-phosphorylation of tau and associated neurodegeneration. FEBS Lett; 566 : 261-269.

Lohmueller KE, Pearce CL, Pike M et al. 2003 :
Meta-analysis of genetic association studies supports a contribution of common variants to susceptibility to common disease. Nat Gent; 33 : 177-182.

Loos RJ, Lindgren CM, Li S et al. 2008 : Common variants near MC4R are associated with fat mass, weight and risk of obesity. Nat Genet; 40 : 768-775.

Luchsinger JA 2008 : Adiposity, hyperinsulinemia, diabetes and Alzheimer's disease : an epidemiological perspective. Eur J Pharmacol; 585 : 119-129.

Ma L, Wang J and Li Y 2015 : Insulin resistance and cognitive dysfunction. Clin Chim Acta; 444 : $18-23$

Mangialasche F, Solomon A, Winblad B et al. 2010 : Alzheimer's disease : clinical trials and drug development. Lancet Neurol; 9 : 702-716.

Martins IJ, Hone E, Foster JK et al. 2006 : Apolipoprotein E, cholesterol metabolism, diabetes and the convergence of risk factors for Alzheimer's disease and cardio-vascular disease. Mol Psychiatry; 11 : 721-736

Martyn JA, Kaneki M and Yasuhara S 2008 : Obesity-induced insulin resistance and hyperglycemia : etiologic factors and molecular mechanisms. Anesthesiology; 109 : 137-148

Mayeu XR and Stern Y 2010: Epidemiology of Alzheimer disease. Cold Spring Ha Perspect Med; 2.

Mavoa HM and Mc Cabe M 2008: Sociocultural factors relating to Tongans and Indigenous Fijians patterns of eating, physical activity and body size. Asia Pac J Clin Nutr; 17 : 375-384.

Milionis HJ, Florentin $\mathrm{M}$ and Giannopoulos S 2008: Metabolic syndrome and Alzheimer's disease : a link to a vascular hypothesis ? CNS Spectr; 13: 606-613.

Misra A and Khurana L 2008: Obesity and the metabolic syndrome in developing countries. J Clin Endocrinol Metab; 93: S9-30.

Morton GJ, Cumming DE, Baskin DG et al. 2006: Central nervous system control of food intake and body weight. Nature; 443: 289-295.

Nieto-Vazquez I, Fernandez-Veledo S, Kramer 
DK et al. 2008: Insulin resistance associated to obesity: the link TNF-alpha. Arch Physiol Biochem; 114: 183-194.

Peila R, Rodriguez BL, White et al. 2004: Fasting insulin and incident dementia in an elderly population of Japanese American Men. Neurology; $63: 228-233$

Popkin BM 2001: The nutrition transition and obesity in the developing world. J Nutr; 131: 871S873 S.

Prokesch A, Hackl H, Hakim-Weber R et al. 2009 : Novel insights into adipogenesis from omics data. Curr Med Chem; 16: 2952-2964.

Purandare N, Burns A, Daly KJ et al. 2006: Cerebral emboli as a potential cause of Alzheimer's disease and vascular dementia: case-control study. BMJ; 332: 1119-1124.

Qi L and Cho YA 2008: Gene-environment interaction and obesity. Nutr Rev; 66: 684-694.

Qiu C, De Ronchi D and Fratiglioni L 2007: the epidemiology of the dementias: an update. Curr Opin Psychiatry; 20: 380-385.

Querfurth HW, La Ferla FM 2010: Alzheimer's disease. N Engl J Med; 362: 329-344.

Rajasekar N, Nath C, Hanif K et al. 2017: Intranasal insulin administration ameliorates streptozotocin (ICV)-induced insulin receptor dysfunction, neuroinflammation, amyloidogenesis and memory impairment in rats. Mol Neurobiol; 54: 6507-6522.

Rani V, Deshmukh R, Jaswal $\mathrm{P}$ et al. 2016: Alzheimer's disease : Is this a brain specific diabetic condition? Physiol Behav; 164: 259-267.

Ritchie K and Lovestone S 2002: The dementias. Lancet; 360: 1759-1766.

Sangiovanni, E. Vrhovsek, U. Rossoni, G. 2013 Ellagitannins from Rubus berries for the control of gastric inflammation: In vitro and in vivo studies, Polsone; 8(8) e71762.

Sastre M, Walter J and Gentleman SM 2008: Interactions between App secretases and inflammatory mediators. J Neuro-inflammation; 5 : 25

Schattenberg JM, Singh R, Wang Y et al. 2006: JNK1 but not JNK2 promotes the development of steatohepatitis in mice. Hepatology; $43: 163-172$
Schneider LS, Mangialasche F, Andreasen N et al. 2014: Clinical trails and late-stage drug development for Alzheimer disease: an appraisal from 1984 to 2014. J Intern Med; 275: 251-283.

Schulingkamp RJ, Pagano TC, Hung D et al. 2000 : Insulin receptors and insulin action in brain : review and clinical implications. Neurosci Biobehav Rev; 24 : 855-872.

Shagam JY 2009: The many faces of dementia. Radiol Technol; 81: 153-168.

Shoelson Se, Herrero L and Naaz A 2007: Obesity, inflammation and insulin resistance. Gastroenterology; 132:2169-2180

Sowers JR 2003: Obesity as a cardiovascular risk factor. Am J Med; 115 (Suppl.) 8A : 37S-41S

Takashima A 2010: Drug development for tauopathy and Alzheimer's disease. Nihon Shinkei Seishin Yakurigaku Zasshi ;30:177-180

Takei N and Nawa H 2014 : mTOR signaling and its role in normal and abnormal brain development. Front Mol Neurosci; 7: 28.

Tan JT, Dorajoo R, Seielstad M et al. 2008: FTO variant are associated with obesity in the Chinese and Malay populations in Singapore. Diabetes; 57 : 2851-2857.

Thinakaran G and Koo EH 2008: Amyloid precursor protein trafficking processing and function. J Biol Chem; 283: 29615-29619.

Tilg $\mathrm{H}$ and Moschen AR 2008: Inflammatory mechanisms in the regulation of insulin resistance. Mol Med; 14: 222-231.

Valdecantos MP, Perez-Matute P and Martinez JA 2009: Obesity and oxidative stress : role of antioxidant supplementation. Rev Invest Clin; 16: 127-139.

Van der Auweral I, Wera S, Van Leuven F et al. 2005: A ketogenic diet reduces amyloid beta 40 and 42 in a mouse model of Alzheimer's disease. Nutr Metab (Lond); 2 : 28.

Van Rensburg SJ, Van Zyl JM, Potocnik FC et al. 2006: The effect of stress on the antioxidative potential of serum: implications for Alzheimer's disease. Metab Brain Dis; 21: 171-179.

Verdile G, Keane KN, Cruzat VF et al. 2015 : Inflammation and oxidative stress : The 
molecular connectivity between insulin resistance, obesity and Alzheimer's disease. Mediators Inflamm; $2015: 105828$.

Vincent HK, Innes KE and Vincent KR 2007: Oxidative stress and potential interventions to reduce oxidative stress in overweight and obesity. Diabetes Obes Metab; 9:813-839.

Wasir JS and Misra A 2004: The metabolic syndrome in Asian Indians : Impact of nutritional and socioeconomic transition in India Metab Syndr. Relat Disord; 2: 14-23.

Weingarten MD, Lockwood AH, Hwo SY et al. 1975 : A protein factor essential for microtubule assembly. Proc Natl Acad Sci USA; 72: 18581862.

Wellen KE and Hotamisligil GS 2005 : Inflammation, stress and diabetes. J Clin Invest; $112: 1796-1808$

Wen MM, El-Salamouni NS, El-Refaie et al. 2017 : Nanotechnology-based drug delivery systems for Alzheimer's disease management : Technical industrial and clinical challenges. J Control Release; 245: 95-103.

Xu W, Qiu, C, Sinblad B et al. 2007: The effect of borderline diabetes on the risk of dementia and Alzheimer's disease. Diabetes; 56: 211-216. 